\title{
Urinary Tract Infection in Children - Onset of a New Era?
}

\author{
Tanja Kersnik Levart and Rajko B Kenda \\ University Medical Center Ljubljana \\ Division of Paediatrics, Department of Nephrology \\ Ljubljana \\ Slovenia
}

\section{Introduction}

The prevalence of urinary tract infection (UTI) in febrile infants, young children and older children with urinary symptoms and/or fever is 7 to 8 percent and varies by age, race, sex, and circumcision status $(1,2,3)$. White children have a two- to four-fold higher prevalence of UTI than black children. The same proportion can be found among girls and circumcised boys.

\section{Microbiology}

Eighty-five percent of UTI in children is caused by Escherichia coli (E. coli). Other gramnegative bacteria include Klebsiella, Proteus, Pseudomonas, Enterobacter, and Citrobacter. Gram-positive bacteria include Staphylococcus saprophyticus, Enterococcus, and, rarely, Staphylococcus aureus. Non-E. coli UTI is more often associated with urinary tract anomalies, younger age, and previous antibiotic treatment (4). Viruses and fungi are uncommon causes of UTI in children $(5,6)$.

\section{Pathogenesis}

Most UTIs beyond the newborn period are the result of ascending infection, while only a minority of them result from bacteremia $(7,8)$. Bacterial-host interactions are major factors in UTI taking place, and occur when bacterial factors prevail over the hosts.

Bacterial factors that interact with the host and can cause UTI include the ability to colonize the periurethral area, the ability to ascend into the bladder and kidneys, and the ability to generate inflammatory response. Colonization of the periurethral area by uropathogenic enteric pathogens is the first step in the development of UTI. The bacteria ascend into the bladder and kidneys by a variety of virulence factors. The best-studied virulence factors in E. coli are pili, hair-like appendages on the cell surface. Bacteria possessing pili can adhere effectively to the uroepithelium and ascend into the kidneys, even in children without vesicoureteric reflux (VUR). In the kidneys, the bacterial inoculum generates an intense inflammatory response, which may ultimately lead to renal scarring $(9,10)$.

Young age (males younger than one year and females younger than four years), phymosis, female sex, white race, genetic factors, urinary tract obstruction, dysfunctional voiding, 
VUR, sexual activity, and duration of bladder catheterization are some host factors influencing the predisposition to UTI in children (1-3, 11-18).

\section{Clinical presentation}

Children with UTI can present with various symptoms and signs, depending largely on the site of infection (lower or upper urinary tract) and the age of the child. Infants and young children can present with very nonspecific symptoms ranging from life-threatening urosepsis to asymptomatic bacteriuria, whereas the clinical presentation of UTI in older children can be very similar to that of adults. Fever, poor feeding, irritability, failure to thrive, conjugated hyperbilirubinemia, gastrointestinal symptoms, convulsions, hypotension, pallor and cyanosis are some nonspecific symptoms of UTI in infants. The symptoms of UTI in older children may include fever, urinary symptoms (dysuria, urgency, frequency, incontinence, macroscopic hematuria), and abdominal pain (19-21). The constellation of fever, chills, and flank pain is suggestive of pyelonephritis in older children (22).

\subsection{Clinical and laboratory evaluation}

The evaluation of a child with suspected UTI should include a history of the acute illness and relevant information from his/her past medical history about chronic urinary symptoms, chronic constipation, previous UTI, VUR, previous undiagnosed febrile illnesses, family history of frequent UTIs, VURs and other genitourinary abnormalities, antenatally diagnosed renal abnormality, elevated blood pressure, poor growth and, in sexually active girls, whether barrier contraception with spermicidal agents is used (23).

Following the detailed history evaluation, a child should have a physical examination concentrating on his/her general well-being, including failure to thrive, body temperature, blood pressure, abdominal examination for tenderness and mass, assessment of suprapubic and costovertebral tenderness, examination of external genitalia for anatomic abnormalities, evaluation of the lower back for signs of occult myelodysplasia, and evaluation for other sources of fever.

The laboratory evaluation of a child with suspected UTI should obligatorily include the collection of a urine sample for dip-stick and microscopic analysis and urine culture, the last being necessary to make the diagnosis of UTI.

Obtaining a proper urine sample is of prime importance for the proper diagnosis of UTI in children. In general, there are invasive in noninvasive ways of obtaining urine samples in children. Suprapubic aspiration of the bladder and bladder catheterization are invasive procedures. Although the first is not without danger for the patient, it is the most accurate way of obtaining a urine sample. The second method is used only when a catheter is inserted into the bladder for other reasons, such as performing a cystography. We believe that both invasive procedures are not suitable for use in outpatient clinics, and should be strictly reserved for use in hospitals whenever needed. In toilet-trained children, the most widely used and preferred method of collecting urine is the noninvasive clean-catch. In infants and young children who are not toilet-trained, urine can be obtained in a urine bag. However, up to 85 percent of positive cultures from bag specimens give false-positive results, and therefore the results of urine cultures from bag specimens are useful only if they are negative (24). A better alternative to the urine bag is the urine collector designed by Kenda in 1993, which is actually a plastic, sterile, disposable urine collector that highly 
resembles the urine bag, except for the plastic tube in which the final portion of urine is caught (25-27). The collector is attached via a self-adhesive strip in the same way as the urine bag. During micturition, urine flows through a funnel extending into a tube, which is encircled by a test tube, and flows further into a second chamber (urine bag). Urine is finally collected in the bag, except for the very last portion, which is caught in the test tube, free of contaminants from the urethra. The test tube is separated from the collector, sealed with a lid and sent to the laboratory (Figure 1).

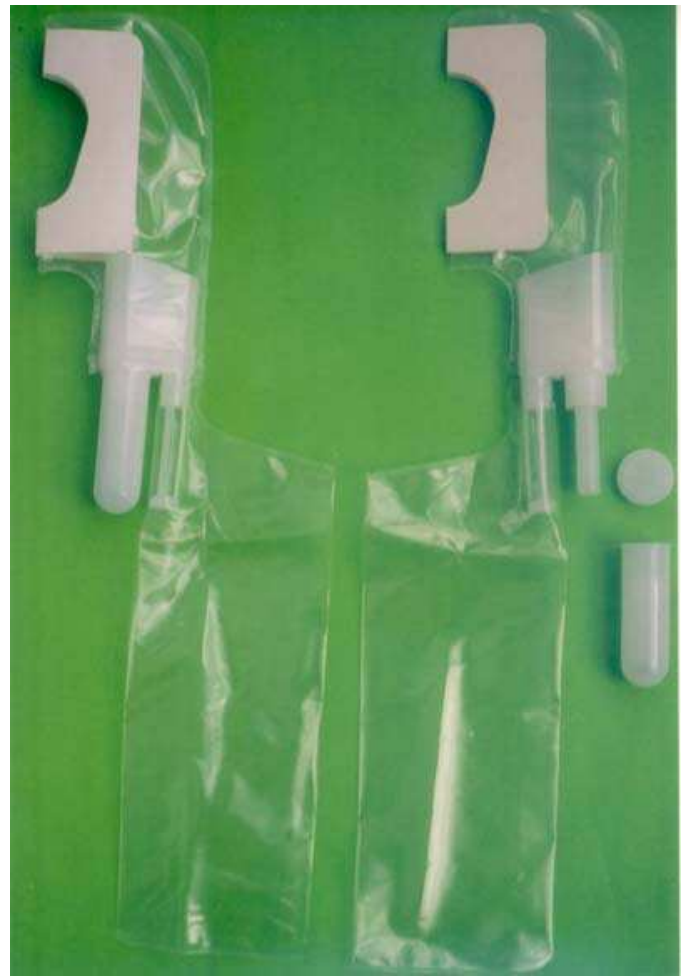

Fig. 1. The paediatric midstream urine collector.

When a proper urine sample is obtained, it can be tested for significant bacteriuria with the following more or less reliable tests:

- Dipstick analysis - Dipstick tests are convenient, inexpensive, require little training for proper usage, and may be the only test available in some settings. However, they do not have a sufficiently high specificity and sensitivity for detecting UTI to replace the urine culture (28). The most suggestive for UTI on dipstick analysis is the presence of leukocyte esterase and nitrite. The presence of leukocyte esterase is suggestive of UTI, but does not always signal a true UTI. A child with a positive nitrite test is likely to have UTI, since the nitrite test is highly specific and has a low false-positive rate. However, false-negative results are common, because urine needs to remain in the bladder for at least four hours to accumulate a detectable amount of nitrite. Thus, the negative nitrite test does not exclude UTI. 
- Microscopic exam - A microscopic examination requires more equipment and training than dipstick tests. In standard microscopy, a centrifuged sample of unstained urine is examined for white blood cells (WBC) and bacteria. When performed in this way, pyuria is defined as $\geq 5 \mathrm{WBC} /$ high power field (hpf) and bacteriuria as the presence of any bacteria per hpf. The sensitivity of the standard microscopic examination conducted using a centrifuged urine specimen is at best 81 percent.

- Urine culture - Quantitative urine culture is the gold standard for diagnosing UTI, and should be performed in any child with suspected UTI before antibiotic treatment is started.

There are other laboratory tests that can help to diagnose UTI in children, but are not particularly helpful. These include:

- Markers of inflammation - Elevated peripheral white blood cell (WBC), erythrocyte sedimentation rate (ESR), C-reactive protein (CRP), and procalcitonin (PCT) are indicators of an acute inflammatory process. These markers are associated with upper urinary tract infection. Even though they do not always reliably differentiate between children with cystitis and children with pyelonephritis, we believe that a febrile child with elevated markers of inflammation and culture proven UTI does not need a dimercaptosuccinic acid renal scan (DMSA) to prove acute pyelonephritis.

- Serum creatinine - Measurement of serum creatinine is not routinely necessary in children with suspected UTI. However, it should be measured in children with a history of multiple UTI and suspected renal involvement.

- Blood culture - Bacteremia occurs in 4 to 9 percent of infants with UTI $(29,30)$. Fever in bacteremic infants with UTI persists, on average, one day longer than in nonbacteremic infants with UTI (31). However, a positive blood culture does not alter management, except for the length of treatment, in the vast majority of children because the organisms isolated from the blood and urine are usually identical. Blood culture should be routinely performed in the neonatal period, and thereafter it should be taken on the basis of clinical judgment.

- Lumbar puncture - Infants under 1 month of age with fever and a positive urinalysis should have a lumbar puncture performed; approximately 1 percent of infants with UTI also have bacterial meningitis (32).

\section{Diagnosis}

In a child with suspected UTI, a urine sample should be taken. The methods of obtaining a proper urinary sample are described in the previous section (Clinical and laboratory evaluation). The urine sample should be cultured, since a urinary culture of properly collected urine sample is the standard test for UTI diagnosis. A positive urinary culture or significant bacteriuria is defined as 100,000 or more colony-forming units (CFU)/ $\mathrm{ml}$ of urine taken with a clean-catch, urine bag, or urine collector. The number may be lower in small children, who empty the bladder more frequently, and any bacterial growth in urine taken by suprapubic aspiration of the bladder signifies a significant bacteriuria. When culturing urine samples, one may encounter logistic problems. Not all doctors have the possibility of sending a urine sample to the microbiology laboratory at any time of the day. Urine samples can be stored at 4 degrees Celsius up to 24 hours and sent to the laboratory once daily, while on the other hand many logistic problems can be solved with the use of semi-quantitative dip-slide urine cultures. These are cheap accessories of different manufacturers, composed 
of a sterile pot containing a bar covered with an agar for bacterial growth. All bacteria can grow on one side of the agar (agar CLED), while the other side is designed for the growth of gram negative bacteria (agar MacConkey). In addition to agar CLED and MacConkey, there is a special agar for Echerichia coli in a semi-quantitative dip-slide urine culture named Uricult-trio (Figure 2). Due to their many advantages, semi-quantitative urine cultures are very useful in private medical examinations, as well as in welfare centers and hospitals. Compared to quantitative urine cultures, they are several folds cheaper, do not require transport to the microbiology laboratory, are easy to handle, and the results can easily be interpreted and read in 18 to 24 hours. If these are positive, the bar can be sent to a microbiology laboratory for exact isolation and identification of bacteria with an antibiogram.

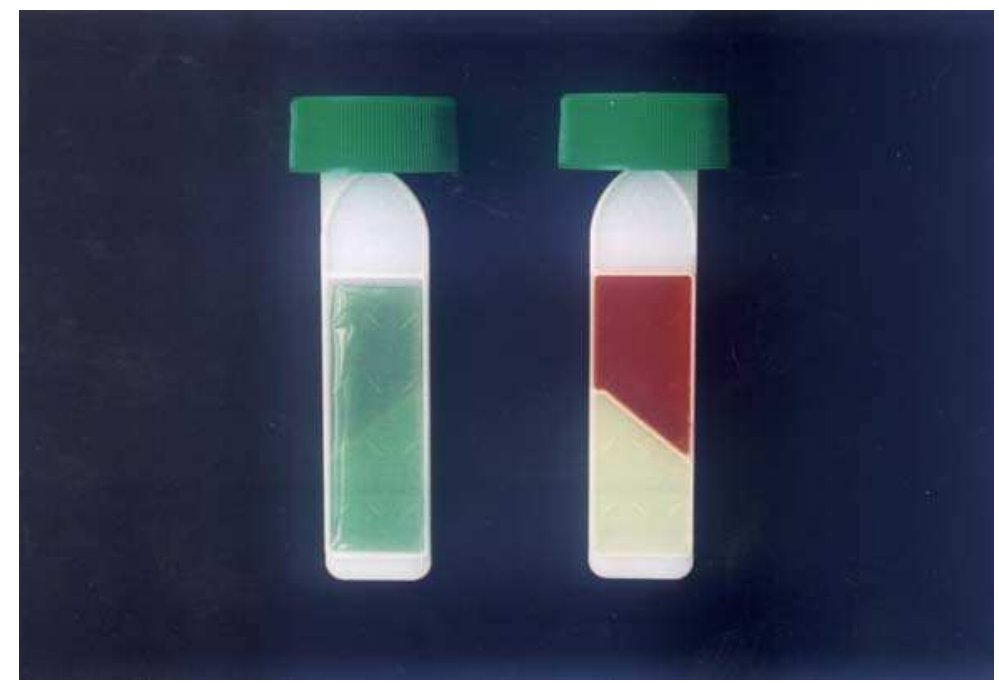

Fig. 2. Uricult-trio.

\section{Diferential diagnosis}

A differential diagnosis in a child with suspected UTI includes all diseases that present with fever, failure to thrive, abdominal pain, or urinary symptoms (urgency, frequency, dysuria). The older the child, the easier it is to differentiate between upper and lower UTI.

\section{Treatment}

Prompt recognition and treatment of UTI are important factors in the prevention of renal scarring. The site of UTI (upper or lower), general welfare of a child and his/her age are major factors that dictate management. There is, however, no doubt that in young children who are at increased risk for UTI on the basis of demographic and clinical factors, as well as in children with underlying urologic abnormalities, treatment should be started immediately after urine was taken for culture and before the results are obtained. Treatment can be postponed only in cases when the child is well, has little or no symptoms of UTI, and the urine results (dipsticks analysis, microscopic examination) are uncertain. In such cases, 
the results of urine culture are awaited before treating the child, and the urine culture is repeated. Children with asymptomatic bacteriuria should be treated as long urinary tract anomalies are not excluded with an appropriate history, clinical evaluation and urinary tract imaging; thereafter they are treated only if they are symptomatic.

Antibiotics are given as a specific treatment to eliminate infection and prevent urosepsis, while supportive treatment with fluids and antipyretics is also of great importance in relieving acute symptoms. Immediately after urine is taken for culture, the type of antibiotic and the mode of its administration are chosen on the grounds of empirical assumptions about causative bacteria, a knowledge of its resistance, a knowledge of preceding treatment and, above all, on the basis of the child's clinical condition and his/her laboratory results. When the results of urine culture are available, antibiotic treatment is adapted accordingly. In general, most UTIs in children can be treated successfully in 7 to 14 days (33). Shorter treatment is appropriate only in children older than 5 years with proven lower UTI, provided they do not have any urinary tract anomalies.

The decision to hospitalize a child with UTI depends largely on the child's age, the site of UTI (upper or lower), and the child's general well-being. Infants should always be treated in hospital, since many of them are bacteremic and septic $(7,8)$. The same is true of all other children with acute pyelonephritis if they are very ill and show clinical signs of urosepsis, immunocompromised patients, patients who vomit or are unable to tolerate oral medication, and patients who fail to respond to outpatient therapy or if there is a lack of adequate outpatient follow-up $(34,35)$. When these children get better, the antibiotic treatment can be continued and finished orally at home.

Empiric antibiotic therapy for UTI in children should include an antibiotic that provides adequate coverage for E. coli. The agent of choice should, however, be guided by local resistance patterns. Second- and third-generation cephalosporins (eg, cefprozil, cefpodoxime, cefixime, cefotaxime, ceftriaxone) and aminoglycosides (eg, gentamicin, amikacin) are appropriate first-line agents for the empiric treatment of UTI in children. However, these drugs are not effective in treating Enterococcus and should not be used for patients in whom enterococcal UTI is suspected (eg, those with a urinary catheter in place, instrumentation of the urinary tract, or an anatomical abnormality). In such patients, amoxicillin or ampicillin should be added.

There is no firm consensus on the usage of the antibiotic prophylaxis and its duration. The available proof does not justify its broad usage. Moreover, a growing number of reports advise against it, and recommend its usage only in selected groups of patients in whom there is no proof of its inefficacy. In such cases, it seems wise to use it until the condition for which it was taken subsides. Taking into account the above mentioned, prophylaxis is still prescribed to the following groups of children (36):

- children after their first UTI until urinary tract imaging is performed,

- children who are at risk for renal scarring and/or urosepsis (these include children with VUR, especially if it is high-grade, children who are very young or already have scars; other risk factors are also recidivated UTI or obstructive uropathy),

- children with infected kidney stones,

- children without urinary tract anomalies, but with very disturbing, recidivated lower UTI.

The antibiotics used in small doses once daily (in the evening) for long-term prophylaxis are: trimetoprim-sulfomethoxason, nitrofurantoin and, rarely, cefaclor or amoxicillin with clavulanic acid (in infants) (37). 


\section{Management of children after urinary tract infection}

Children with UTI should be investigated after their first UTI for possible urinary tract anomalies. The extent of investigations depends largely upon the age of the child, micturation habits and history of possible voiding dysfunction.

In recent decades, a significant change in the management of children after UTI has occurred. It was long believed that vesicoureteric reflux (VUR) of infected urine or even sterile VUR of high grade per se can lead to renal scarring and progressive chronic kidney disease (38-40). Lately, however, such a role of VUR has been questioned by many authors (41-50). It is no wonder that the diagnostic algorithm for children after UTI has changed, and it is hard to expect that a unified approach can be unanimously agreed upon. Those who believe that VUR as such is an important risk factor for renal scarring still favor its detection in all children after proven UTI (51). On the other hand, there is a growing number of pediatric nephrologists who prefer screening for scars (mostly using a 99mTcdimercaptosuccinic acid renal scan (DMSA)), and recommend cystography (preferably Xray voiding cystourethrography (VCUG)) only in those cases where renal scarring has been confirmed (41-50). Regardless which approach one finds closer to one's opinion, there should nevertheless be general agreement that the ongoing search for patient-friendly investigations should be an imperative in taking care of the children in question. In addition, when in doubt whether a child benefits from our knowledge of an existing problem, the decision to perform the procedure in question seems more justified when it is simple, painless, radiation-free and noninvasive.

There is really no data to support the assertion that all children after UTI require investigation; however, there is also no convincing data to support the assertion that they do not. Until this dilemma is solved, we believe that all children after UTI still deserve investigation where, in a growing number of cases, ultrasonography (US) and investigations using US techniques appear to be sufficient.

\section{Management of children after urinary tract infection with emphasis on detection of vesicoureteric reflux}

The chronological development of techniques for VUR detection is schematically presented in Figure 3.

Twenty years ago, X-ray voiding cystourethrography (VCUG) was the only method for VUR detection and until not long ago it was considered a gold standard method. In order to diminish the radiation burden on patients, radionuclide voiding cystography (RVC) was introduced some 15 years ago. Unfortunately, in spite of its lower radiation burden and confirmed better sensitivity, it has not replaced VCUG in all justified cases. It was only with the development of new echo contrast agents that echo-enhanced voiding urosonography (VUS) was offered as an alternative. So far, numerous studies have confirmed that its sensitivity and specificity are high enough to allow it to be introduced as a routine method (52-56). It should be noted that this was the first method with no radiation at all, while the fact that catheterization is still necessary, as in VCUG and RVC, posed a drawback to those who strongly opposed catheterization as such. It was therefore not surprising that various investigators were vigorously searching for a noninvasive (catheter-free) method that would still provide all the necessary information regarding VUR. Till now, a number of such methods for VUR detection have been described, i.e. noninvasive radionuclide voiding cystography, noninvasive voiding urosonography, measurement of midline to orifice 
distance, Color Flow Doppler ultrasonography, and Ureteric jet Doppler Waveform (UJDW) measurement.

\section{Detection of VUR as such}

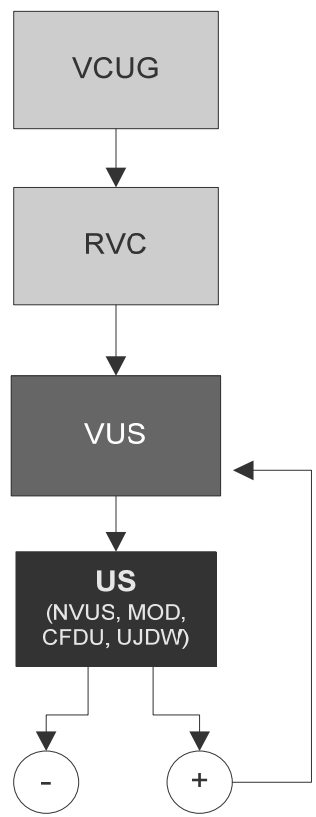

VUR - vesicoureteric reflux, VCUG - X-ray voiding cystourethrography, RVC - radionuclide voiding cystography, VUS - echo-enhanced voiding urosonography, NVUS - noninvasive voiding urosonography, MOD - midline to orifice distance measurement, CFDU - Color Flow Doppler ultrasonography, UJDW - Ureteric jet Doppler Waveform measurement, US - ultrasonography

Fig. 3. Schematic presentation of the chronological development of techniques for vesicoureteric reflux detection.

Noninvasive radionuclide voiding cystography. This method is based on the use of dynamic renography, and is performed following a dynamic renogram when the child voids spontaneously; a contrast appearing in the kidney suggests VUR (57). Although this is a catheter-free method for VUR detection, it still poses a certain radiation burden to the patient, has relatively low sensitivity, requires venepuncture with intravenous application of a contrast medium, and is more or less a »side-product « of dynamic renography, which does not appear to be the first line investigation when looking for VUR.

All other noninvasive methods for VUR detection are based on the use of US and are therefore radiation-free.

Noninvasive voiding urosonography. An increase in the antero-posterior diameter of the collecting system during and/or after voiding is suggested to be an indirect sign of VUR in noninvasive voiding urosonography. This method was shown to be sensitive enough only 
in detecting high grade VUR. It could probably be used for detecting VUR in toilet-trained children, but at this point there is not sufficient data to recommend it as a routine method for this purpose (58-61).

Measurement of midline to orifice distance. It was suggested that this method be used as an indirect predictor of VUR due to the well-known fact that ureters with more laterally placed ureteric orifices are more likely to be affected by VUR than ureters with orifices that are placed more medially. In spite of being the simplest and the quickest method for VUR detection, data are unfortunately lacking to define a reliable cut-off point suggesting VUR $(62,63)$.

Color Flow Doppler ultrasonography. This method detects any reversal flow from the bladder into the distal ureter as a change in color on the monitor. It was shown to have a relatively high overall sensitivity, while the fact that it must be performed during voiding renders the procedure applicable only in toilet-trained children (63-67).

Ureteric jet Doppler Waveform measurement. In this method, the shape of UJDW is used to predict VUR. At this point, it seems to be the most promising of the above-mentioned methods, especially as a screening method in a two-stage protocol in detecting VUR. If one were to proceed from UJDW measurement to VUS only in those cases where UJDW measurement was indicative for VUR, a considerable number of children over 3 years of age would be spared from one of the invasive micturating cystographies (68-71).

The replacement of VCUG with RVC and finally with VUS presents a significant improvement in diminishing the radiation burden on patients, while the catheter-free procedures presenting a "final solution" remain to be validated. From here on, more studies are needed to define the exact role of each of the latest noninvasive (catheter-free) methods for VUR detection.

\section{Management of children after urinary tract infection with emphasis on the detection of vesicoureteric reflux through its consequences (renal scarring)}

The chronological development of techniques for VUR detection through its consequences (renal scarring) is schematically presented in Figure 4.

In the eighties, intravenous urography was considered the gold standard for renal scar detection, and it was recommended that it be performed in every child together with VCUG after UTI (72). Later on, it was almost completely substituted by DMSA, and is nowadays recognized as an obsolete method for this purpose due to the radiation hazard and side effects caused by the contrast medium. At the same time, the role of VUR as a predisposing factor for renal scarring has been questioned by many pediatric nephrologists. It was therefore suggested that VUR should be looked for (mostly using VCUG) only in those cases where renal scars had been confirmed by DMSA. The latter is recognized as the most sensitive method for renal scar detection (73-75), but it unfortunately involves a relatively high radiation load for the patient and can only be performed in nuclear medicine departments. However, even when following this protocol, which differs significantly from the one described above, a less invasive and user friendly approach can be achieved. There are reports confirming that US, a harmless and widely available method, can be used as a safe and efficient substitute for DMSA in the detection and follow-up of children with renal scars $(76,77)$. These papers are based on the assumption that although US is less sensitive than DMSA in detecting renal scars, it might well be the other way around, namely, that DMSA is too sensitive and detects scars that are too small to be clinically significant, while 


\section{Detection of VUR through its consequences (renal scarring)}

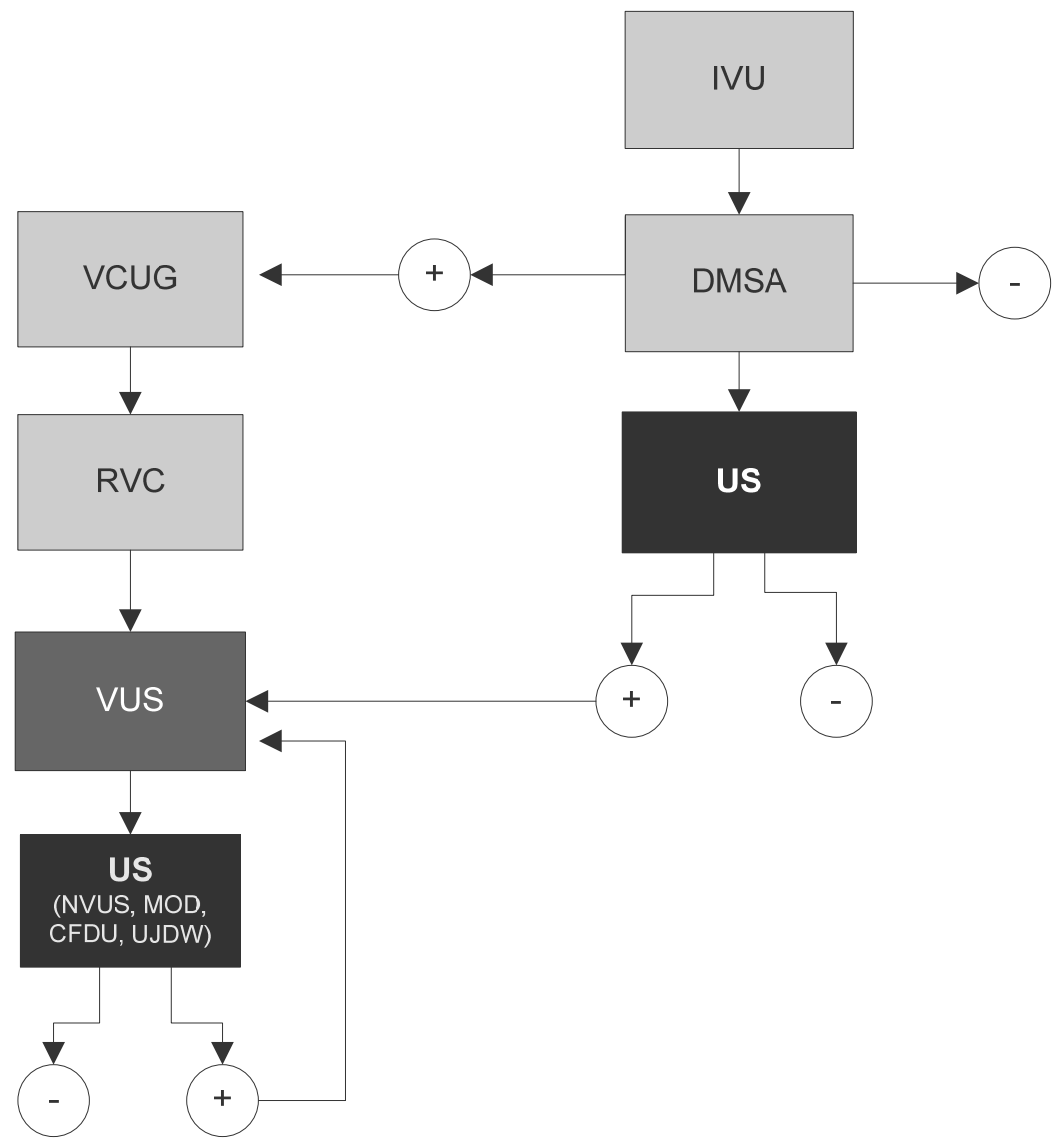

VUR - vesicoureteric reflux, VCUG - X-ray voiding cystourethrography, RVC - radionuclide voiding cystography, VUS - echo-enhanced voiding urosonography, NVUS - nonivasive voiding urosonography, MOD - midline to orifice distance measurement, CFDU - Color Flow Doppler ultrasonography, UJDW - Ureteric jet Doppler Waveform measurement, IVU - intravenous urography, DMSA - 99mTc-dimercaptosuccinic acid renal scan, US - ultrasonography

Fig. 4. Schematic presentation of chronological development techniques for vesicoureteric reflux detection through its consequences (renal scarring). 
US is sensitive enough to detect clinically significant scars. This assumption was proved by stratifying DMSA results according to the extent of renal scarring, and correlating them to clinical parameters suggestive of renal impairment in our latest studies $(76,77)$. Furthermore, when one follows this protocol, which suggests VCUG only in those children with proven scars, we believe there is enough evidence supporting the statement that the sensitivity and specificity of VUS is high enough for it to replace VCUG $(52,56)$. In other words, DMSA could be replaced by US and VCUG by VUS, while the role of new, catheterfree US techniques for VUR detection, as already described, has yet to be validated.

\section{Conclusions}

Urinary tract infections (UTI) are common and still an important clinical problem in children. Most UTIs beyond the newborn period are the result of ascending infection, while only a minority of them result from bacteremia. Bacterial-host interactions are major factors in the pathogenesis of UTI.

Children with UTI can present with various symptoms and signs that may be very nonspecific, especially in infants and young children, depending largely on the site of infection (lower or upper urinary tract) and the age of the child.

Prompt recognition and treatment of UTI are important factors in the prevention of renal scarring. The gold standard method of proving UTI is a positive urine culture of a properly obtained urine sample. Antibiotics are given as a specific treatment, while fluids and antipyretics are given as a supportive treatment.

Children with UTI should be investigated after their first UTI for possible urinary tract anomalies. The extent of investigations depends largely on the age of the child, his/her micturation habits and history of possible voiding dysfunction. In recent decades, a significant change in the management of children after UTI has occurred. There is no data to support the assertion that all children after UTI require investigation; however, there is also no convincing data to support the assertion that they do not. Until this dilemma is solved, we believe that all children after UTI still deserve investigation, where, in a growing number of cases, ultrasonography (US) and investigations using US techniques appear to be sufficient.

\section{References}

[1] Hoberman A, Chao HP, Keller DM, Hickey R, Davis HW, Ellis D. Prevalence of urinary tract infection in febrile infants. J Pediatr. 1993;123(1):17.

[2] Shaw KN, Gorelick M, McGowan KL, Yakscoe NM, Schwartz JS. Prevalence of urinary tract infection in febrile young children in the emergency department. Pediatrics. 1998;102(2):e16.

[3] Shaikh N, Morone NE, Bost JE, Farrell MH. Prevalence of urinary tract infection in childhood: a meta-analysis. Pediatr Infect Dis J. 2008;27(4):302.

[4] Friedman S, Reif S, Assia A, Mishaal R, Levy I. Clinical and laboratory characteristics of non-E. coli urinary tract infections. Arch Dis Child. 2006;91(10):845.

[5] Wald, ER. Cystitis and pyelonephritis. In: Textbook of Pediatric Infectious Diseases, 6th ed, Feigin, RD, Cherry, JD, Demmler-Harrison, GJ, Kaplan, SL (Eds), Saunders, Philadelphia, 2009. p. 554. 
[6] Sobel JD, Vazquez JA. Fungal infections of the urinary tract. World J Urol. 1999;17(6): 410.

[7] Zorc JJ, Kiddoo DA, Shaw KN. Diagnosis and management of pediatric urinary tract infections. Clin Microbiol Rev. 2005;18(2):417.

[8] Struthers S, Scanlon J, Parker K, Goddard J, Hallett R. Parental reporting of smelly urine and urinary tract infection. Arch Dis Child. 2003;88(3):250.

[9] Godaly G, Bergsten G, Hang L, Fischer H, Frendéus B, Lundstedt AC, Samuelsson M, Samuelsson P, Svanborg C. Neutrophil recruitment, chemokine receptors, and resistance to mucosal infection. J Leukoc Biol. 2001;69(6):899.

[10] Svanborg C, Bergsten G, Fischer H, Godaly G, Gustafsson M, Karpman D, Lundstedt AC, Ragnarsdottir B, Svensson M, Wullt B. Uropathogenic Escherichia coli as a model of host-parasite interaction. Curr Opin Microbiol. 2006;9(1):33.

[11] Mårild S, Jodal U. Incidence rate of first-time symptomatic urinary tract infection in children under 6 years of age. Acta Paediatr. 1998;87(5):549.

[12] Singh-Grewal D, Macdessi J, Craig J. Circumcision for the prevention of urinary tract infection in boys: a systematic review of randomised trials and observational studies. Arch Dis Child. 2005;90(8):853.

[13] Mårild S, Wettergren B, Hellström M, Jodal U, Lincoln K, Orskov I, Orskov F, Svanborg Edén C. Bacterial virulence and inflammatory response in infants with febrile urinary tract infection or screening bacteriuria. J Pediatr. 1988; 112(3):348.

[14] Lundstedt AC, Leijonhufvud I, Ragnarsdottir B, Karpman D, Andersson B, Svanborg C. Inherited susceptibility to acute pyelonephritis: a family study of urinary tract infection. J Infect Dis. 2007;195(8):1227.

[15] Jantausch BA, Criss VR, O'Donnell R, Wiedermann BL, Majd M, Rushton HG, Shirey RS, Luban NL. Association of Lewis blood group phenotypes with urinary tract infection in children. J Pediatr. 1994;124(6):863.

[16] Sheinfeld J, Schaeffer AJ, Cordon-Cardo C, Rogatko A, Fair WR. Association of the Lewis blood-group phenotype with recurrent urinary tract infections in women. $\mathrm{N}$ Engl J Med. 1989;320(12):773.

[17] Ragnarsdóttir B, Samuelsson M, Gustafsson MC, Leijonhufvud I, Karpman D, Svanborg C. Reduced toll-like receptor 4 expression in children with asymptomatic bacteriuria. J Infect Dis. 2007;196(3):475.

[18] Haraoka M, Hang L, Frendéus B, Godaly G, Burdick M, Strieter R, Svanborg C. Neutrophil recruitment and resistance to urinary tract infection. J Infect Dis. 1999;180(4):1220.

[19] Winberg J, Andersen HJ, Bergström T, Jacobsson B, Larson H, Lincoln K. Epidemiology of symptomatic urinary tract infection in childhood. Acta Paediatr Scand Suppl. 1974;(252):1.

[20] Majd M, Rushton HG, Jantausch B, Wiedermann BL. Relationship among vesicoureteral reflux, P-fimbriated Escherichia coli, and acute pyelonephritis in children with febrile urinary tract infection. J Pediatr. 1991;119(4):578.

[21] Smellie JM, Hodson CJ, Edwards D, Normand IC. Clinical and radiological features of urinary infection in childhood. Br Med J. 1964;2(5419):1222. 
[22] Zorc JJ, Kiddoo DA, Shaw KN. Diagnosis and management of pediatric urinary tract infections. Clin Microbiol Rev. 2005;18(2):417.

[23] Hooton TM, Scholes D, Stapleton AE, Roberts PL, Winter C, Gupta K, Samadpour M, Stamm WE. A prospective study of asymptomatic bacteriuria in sexually active young women. N Engl J Med. 2000;343(14):992.

[24] Downs SM. Technical report: urinary tract infections in febrile infants and young children. The Urinary Tract Subcommittee of the American Academy of Pediatrics Committee on Quality Improvement. Pediatrics. 1999;103(4):e54.

[25] Kenda RB, Trebše R. New paediatric urine collector. Acta Paediatr. 1998;87(1):98.

[26] Kenda RB. Intercepting apparatus sampling urine for examination purposes. US Patent 1993;5:255 689.

[27] Kenda RB. Urine sampling apparatus. European Patent 1995;0:510 536 B1.

[28] Gorelick MH, Shaw KN. Screening tests for urinary tract infection in children: A metaanalysis. Pediatrics. 1999;104(5):e54.

[29] Smellie JM, Poulton A, Prescod NP. Retrospective study of children with renal scarring associated with reflux and urinary infection. BMJ. 1994;308(6938):1193.

[30] Hoberman A, Wald ER, Hickey RW, Baskin M, Charron M, Majd M, Kearney DH, Reynolds EA, Ruley J, Janosky JE. Oral versus initial intravenous therapy for urinary tract infections in young febrile children. Pediatrics. 1999;104(1 Pt 1):79

[31] Honkinen O, Jahnukainen T, Mertsola J, Eskola J, Ruuskanen O. Bacteremic urinary tract infection in children. Pediatr Infect Dis J. 2000;19(7):630.

[32] Bachur R, Caputo GL. Bacteremia and meningitis among infants with urinary tract infections. Pediatr Emerg Care. 1995;11(5):280.

[33] Čižman M, Beović B, Marolt Gomišček M. Priporočila za uporabo protimikrobnih zdravil. Ljubljana: Tiskarna Povše; 2006.

[34] Chang SL, Shortliffe LD. Pediatric urinary tract infections. Pediatr Clin North Am. 2006;53(3):379.

[35] Practice parameter: the diagnosis, treatment, and evaluation of the initial urinary tract infection in febrile infants and young children. American Academy of Pediatrics. Committee on Quality Improvement. Subcommittee on Urinary Tract Infection. Pediatrics. 1999;103(4 Pt 1):843.

[36] Beetz R. May we go on with antibacterial prophylaxis for urinary tract infections? Pediatr Nephrol 2006;21(1):5.

[37] Hansson S, Jodal U. Urinary Tract Infection. In: Avner ED, Harmon WE, Niaudet P, eds. Pediatric Nephrology. $5^{\text {th }}$ ed. Lippincott Williams \& Wilkins; 2003. p. 1007.

[38] Arat BS: Vesicoureteric reflux and renal injury. Am J Kidney Dis 1991;17(5):491.

[39] Smellie JM, Normand IC: Bacteriuria, reflux, and renal scarring. Arch Dis Child 1975;50(8):581.

[40] Mannhardt W, Schofer O, Schulte-Wissermann H: Pathogenic factors in recurrent urinary tract infections and renal scar formation in children. Eur J Paediatr 1986; 145(5):330.

[41] Jodal U, Smellie JM, Lax H, Hoyer PF: Ten-year results of randomized treatment of children with severe vesicoureteral reflux. Final report of the International Reflux Study in Children. Pediatr Nephrol 2006;21(6):785. 
[42] Tamminen-Möbius T, Brunier E, Ebel KD et al: Cessation of vesicoureteral reflux for 5 years in infants and children allocated to medical treatment. International Reflux Study in Children. J Urol 1992;148(5 Pt 2):1662.

[43] Wheeler D, Vimalachandra D, Hodson EM, Roy LP, Smith G, Craig JC: Antibiotics and surgery for vesicoureteral reflux: a meta-analysis of randomized controlled trials. Arch Dis Child 2003;88(8):688.

[44] O'Donnell B. Reflections on reflux. J Urol 2004;172 (4 Pt 2):1635.

[45] Marra G, Oppezzo C, Ardissino G, Dacco V, Testa S, Avolio L et al: Severe vesicoureteral reflux and chronic renal failure: a condition peculiar to male gender? Data from the ItalKid Project. J Pediatr 2004;144(5):677.

[46] Craig JC, Irwig LM, Knight JF, Roy LP: Does treatment of vesicoureteric reflux in childhood prevent end-stage renal disease attributable to reflux nephropathy? Pediatrics 2000;105(6):1236.

[47] Moorthy I, Easty M, McHugh K, Ridout D, Biassoni L, Gordon I: The presence of vesicoureteric reflux does not identify a population risk for renal scarring following a first urinary tract infection. Arch Dis Child 2005;90(7):733.

[48] Gordon I, Barkovics M, Pindoria S, Cole T, Woolf AS: Primary vesicoureteral reflux as a predictor of renal damage in children hospitalized with urinary tract infection: a systemic review and meta-analysis. J Am Soc Nephrol 2003;14:739.

[49] National Institute for Health and Clinical Excellence (NICE): Urinary tract infection in children. http://guidance.nice.org.uk/CG054 2007.

[50] Venhola M, Uhari M: Vesicoureteral reflux, a benign condition. Pediatri Nephrol 2009;24(2):223.

[51] Coulthard MG: Vesicoureteric reflux is not a benign condition. Pediatri Nephrol 2009;24(2):227.

[52] Bosio M: Cystosonography with echocontrast: a new imaging modality to detect vesicoureteric reflux in children. Pediatr Radiol 1998;28(4):250.

[53] Darge K, Duetting T, Zieger B, Mohring K, Roschneider W, Troeger J: Diagnosis of vesicoureteral reflux with echo-enhanced micturation urosonography. Radiology 1998;38(5):405.

[54] Darge K, Troeger J, Duetting T et al: Reflux in young patients: comparison of voiding US of the bladder and retrovesical space with echo enhancement versus voiding cystourethrography for diagnosis. Radiology 1999;210(1):201.

[55] Mentzel HJ, Vogt S, Patzer L et al: Contrast-enhanced sonography of vesicoureteral reflux in children: preliminary results. AJR 1999;173(3):737.

[56] Kenda RB, Novljan G, Kenig A, Hojker S, Fettich JJ: Echo-enhanced ultrasound voiding cystography in children: a new approach. Pediatr Nephrol 2000;14(4):297.

[57] Gordon I, Colarinha P, Fettich JJ et al: Guidelines for indirect radionuclide cystography. Eur J Nucl Med 2001;28(3):BP16.

[58] Hiraoka M, Hori C, Tsukahara $\mathrm{H}$ et al: Vesicoureteral reflux in male and female neonates as detected by voiding ultrasonography. Kidney Inter 1999;55(4):1486.

[59] Hiraoka M, Kasuga K, Hori C, Sudo M: Ultrasonic indicators of ureteric reflux in the newborn. Lancet 1994;343(8896):519. 
[60] Hiraoka M, Hashimoto G, Hori C, Tsukahara H, Konishi Y, Sudo M: Use of ultrasonography in the detection of ureteric reflux in children suspected of having urinary tract infection. J Clin Ultrasound 1997;25(4):195.

[61] Kopač M, Kenig A, Ključevšek D, Kenda RB: Indirect voiding urosonography for detecting vesicoureteral reflux in children. Pediatr Nephrol 2005;20(9):1285.

[62] Marshall JL, Johnson ND, De Campo MP: Vesicoureteric reflux in children: prediction with color Doppler imaging. Radiology 1990;175(2):355.

[63] Oak SN, Kulkarni B, Chaubal N: Color flow Doppler sonography: a reliable alternative to voiding cystourethrogram in the diagnosis of vesicoureteral reflux in children. Urology 1999;53(6):1211.

[64] Nishizawa O, Ishida H, Sugaya K, Kohama T, Harada T, Tsuchida S: Application of Doppler color flow imaging method on the detection of vesicoureteric reflux. Tohoku J Exp Med 1989;159(2):163.

[65] Salih M, Baltaci S, Kiliç S, Anafarta K, Bedük Y: Color flow Doppler sonography in the diagnosis of vesicoureteric reflux. Eur Urol 1994;26(1):93.

[66] Koşar A, Yeşiladă̆ A, Oyar O, Perk H, Gülsoy U: Detection of vesico-ureteric reflux in children by colour-flow Doppler ultrasonography. BJU International 2003; 91(9):856.

[67] Heberlik A: Detection of low-grade vesicoureteric reflux in children by color Doppler imaging mode. Pediatr Surg Int 1997;12(1):38.

[68] Leung VY, Chu W, Yeung CK, Metreweli C: Doppler waveforms of the ureteric jet: an overview and implications for the presence of a functional sphincter at the vesicoureteric junction. Pediatr Radiol 2007;37(5):417.

[69] Leung VY, Metreweli C, Yeung CK: The ureteric jet Doppler waveform as an indicator of vesicoureteric sphincter function in adults and children. An observational study. Ultrasound in Med. \& Biol 2002;28(7):865.

[70] Leung VY, Metreweli C, Yeung CK: Immature ureteric jet Doppler patterns and urinary tract infection and vesicoureteric reflux in children. Ultrasound in Med \& Biol 2002;28(7):873.

[71] Ključevšek D, Ključevšek T, Kersnik Levart T, Kenda RB: Ureteric jet Doppler waveform: is it a reliable predictor of vesicouretric reflux in children? Pediatr Nephrol 2009;24(2):313.

[72] Royal College of Physicians Research Unit Working Group: Guidelines for the management of acute urinary tract infection in childhood. J R Coll Physicians Lond 1991; 25(1):36.

[73] Mackenzie JR: A reveiw of renal scarring in children. Nuclear Medicine Communications 1996;17(3):176.

[74] Moorthy I, Wheat D, Gordon I: Ultrasonography in the evaluation of renal scarring using DMSA scan as the gold standard. Pediatr Nephrol 2004;19(2):153.

[75] Monsour M, Azmy AF, MacKenzie JR: Renal scarring secondary to vesicoureteric reflux. Clinical assessment and new grading. Br J Urol 1987;60(4):320. 
[76] Kersnik Levart T, Kenig A, Fettich JJ, Ključevšek D, Novljan G, Kenda RB: Sensitivity of ultrasonography in detecting renal parenchyma defects in children. Pediatr Nephrol 2002;17(12):1059.

[77] Kersnik Levart T, Ključevšek D, Kenig A, Kenda RB: Sensitivity of ultrasonography in detecting renal parenchyma defects: six years follow-up. Pediatr Nephrol 2009;24(6):1193. 


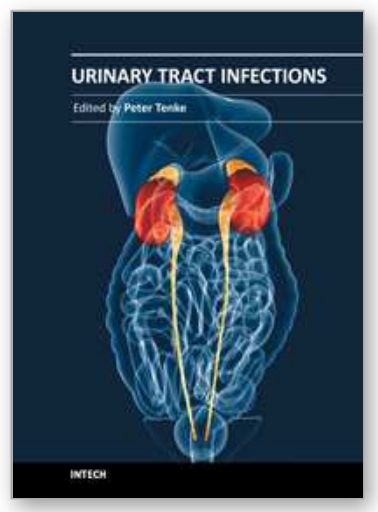

\author{
Urinary Tract Infections \\ Edited by Dr. Peter Tenke
}

ISBN 978-953-307-757-4

Hard cover, 360 pages

Publisher InTech

Published online 30, September, 2011

Published in print edition September, 2011

Urinary tract infections (UTIs) are among the most common bacterial infections worldwide, and they are also the leading cause of hospital-acquired infections. Therefore, the appropriate management of UTIs is a major medical and financial issue. This book covers different clinical manifestations of UTI, with special emphasis on some hard-to-treat diseases, and special conditions in respect of treatment; antibiotic resistance and the available alternative strategies for the prevention and treatment of UTIs and it deals with urinary tract infections in children. The aim of this book is to give a summary about the different aspects of the diagnosis, management and prevention of urinary tract infections for all medical disciplines.

\title{
How to reference
}

In order to correctly reference this scholarly work, feel free to copy and paste the following:

Tanja Kersnik Levart and Rajko B Kenda (2011). Urinary Tract Infection in Children - Onset of a New Era?, Urinary Tract Infections, Dr. Peter Tenke (Ed.), ISBN: 978-953-307-757-4, InTech, Available from: http://www.intechopen.com/books/urinary-tract-infections/urinary-tract-infection-in-children-onset-of-a-newera-

\section{INTECH}

open science | open minds

\section{InTech Europe}

University Campus STeP Ri Slavka Krautzeka 83/A 51000 Rijeka, Croatia

Phone: +385 (51) 770447

Fax: +385 (51) 686166 www.intechopen.com

\section{InTech China}

Unit 405, Office Block, Hotel Equatorial Shanghai No.65, Yan An Road (West), Shanghai, 200040, China 中国上海市延安西路65号上海国际贵都大饭店办公楼 405 单元 Phone: +86-21-62489820

Fax: $+86-21-62489821$ 
(C) 2011 The Author(s). Licensee IntechOpen. This chapter is distributed under the terms of the Creative Commons Attribution-NonCommercialShareAlike-3.0 License, which permits use, distribution and reproduction for non-commercial purposes, provided the original is properly cited and derivative works building on this content are distributed under the same license. 